\title{
Circulação das ideias e internacionalização da Educação Superior: inferências a partir da teoria dos campos de Pierre Bourdieu
}

\author{
Circulation of ideas and internationalization of Higher Education: \\ inferences from Pierre Bourdieu's field theory
}
Circulación de las ideas e internacionalización de la Educación Superior: inferencias a partir de la teoría de los campos de Pierre Bourdieu

\author{
MÁRIO LUIZ NEVES DE AZEVEDO* \\ AFrÂNIO MENDES CATANI** \\ ANA PAULA $\mathrm{HEY}^{* * *}$
}

\begin{abstract}
$\diamond$
\end{abstract}
\begin{abstract}
RESUMO
A partir da teoria dos campos de Pierre Bourdieu, o presente artigo tem por objetivo problematizar a internacionalização da educação superior e a circulação internacional das ideias. Para além da apropriação conceitual, ressalta-se o uso prático do aporte para a compreensão do campo da educação superior no Brasil e a interface com o campo acadêmico. Enfatizam-se os limites e as possibilidades de um campo internacional da educação superior.
\end{abstract}

Palavras-chave: Educação Superior. Campo Social. Campo Acadêmico. Internacionalização. Circulação Internacional de Ideias.

\begin{abstract}
Based on the field theory of the French sociologist Pierre Bourdieu, this article aims to analyse the process of internationalization of higher education and the international circulation of ideas. The article, beyond Pierre Bourdieu's other theoretical contributions, especially emphasizes the approach of "social field theory" to understanding, especially, the "academic field" and/or the "field of higher education".

Keywords: Higher Education. Social field. Academic Field. Internationalization. International Circulation of Ideas.

\section{RESUMEN}

A partir de la teoría de los campos de Pierre Bourdieu, el presente artículo tiene por objetivo problematizar la internacionalización de la educación superior y la circulación internacional de las ideas. Además de la apropiación conceptual, se resalta el uso práctico del aporte para la comprensión del campo de la educación superior en Brasil y la interfaz con el campo académico. Enfatizan los límites y las posibilidades de un campo internacional de la educación superior.

Palabras clave: Educación Superior. Campo Social. Campo Académico. Internacionalización. Circulación Internacional de Ideas.
\end{abstract}

A prática tem uma lógica que não é a da lógica e, consequentemente, aplicar às lógicas práticas a lógica, é arriscar destruir, através de instrumentos que utilizamos para descrevê-la, a lógica que queremos descrever.

(PIERRE BOURDIEU, 1996)

\footnotetext{
* Professor no Departamento de Fundamentos da Educação e Programa de Pós-Graduação em Educação na UEM - Universidade Estadual de Maringá. E-mail: <mlnazevedo@uem.br>.

** Professor Titular na Faculdade de Educação da Universidade de São Paulo (USP), Curso de Graduação em Pedagogia e no Programa de Pós-Graduação em Educação desta Faculdade. Professor no Programa de Pós-Graduação em Integração da América Latina (PROLAM) - USP. Pesquisador do CNPq. E-mail: <amcatani@usp.br>.

*** Professora no Departamento de Sociologia, curso de Ciências Sociais, e no Programa de Pós-Graduação em Sociologia da Faculdade de Filosofia, Letras e Ciências Humanas da Universidade de São Paulo.E-mail: <anahey@usp.br>.
} 
Quais são as lógicas que permeiam a relação entre a circulação das ideias e a internacionalização da educação superior no Brasil? Como se concretiza em estado prático o convite à internacionalização dos acadêmicos, das instituições ou dos atores implicados na formação universitária? Por que, em síntese, tomar como objeto deste artigo a problematização da Internacionalização da Educação Superior? Esta última pergunta remete-nos ao que afirmaram Morosini e Nascimento em artigo recente sobre a questão:

a internacionalização da educação superior vem se constituindo em um dos principais motes da universidade na contemporaneidade. Via de regra, ela está relacionada à qualidade, à excelência, à inovação, ao conhecimento e a outros diferentes temas, destacando-se, na grande parte das vezes, a contribuição positiva dessa presença $(2017$, p. 2).

As palavras dos autores aliadas à epígrafe inicial demonstram, de imediato, que a relevância do tema já implica um estado prático, ou seja, já se observam alterações na figuração institucional, nas políticas científicas e nas disposições dos atores sociais sujeitos a tal processo (acadêmicos, professores, alunos). Assim, vale notar que a internacionalização da educação superior, acompanhada da circulação das ideias - objetivadas na produção acadêmica -, envolve um processo impregnado de elementos e características das estruturas sociais típicas do estado nacional. O texto, entendido como discurso ou tomada de posição, ao circular, carrega os elementos contextuais e as marcas históricas dos espaços produtores de conhecimento. Ademais, os próprios intelectuais (autores, leitores e propagadores), atores sociais fundamentais para a circulação das ideias, longe de portarem a neutralidade transportam suas tomadas de posição - visões de mundo sobre a atividade científica, o estado, a política, a economia e, sobretudo, as relações entre estas esferas. Como lembra Bourdieu, em conferência no Centro Francês da Universidade de Friburgo,

os intelectuais transmitem, quase tanto quanto os outros, preconceitos, estereótipos, ideias, representações muito sumárias, elementares, que se alimentam de acidentes da vida cotidiana, de incompreensões, mal-entendidos (...) (2002, p. 3) ${ }^{1}$.

Com esta preocupação e pretendendo a construção de um verdadeiro 'internacionalismo', Bourdieu propõe

\footnotetext{
"Les intellectuels véhiculent, presque autant que les autres, des préjugés, des stéréotypes, des idées reçues, des représentations très sommaires, très élémentaires, qui se nourrissent des accidents de la vie quotidienne, des incompréhensions, des malentendus (...)" (2002, p.3).
}

que se crie "Um programa europeu de pesquisa científica sobre as relações científicas europeias" crítica o sociólogo, em tal conferência, demonstra desconfiança no "laissez-faire" em matéria de circulação cultural, asseverando que

quanto à cultura, como em outros assuntos, não acredito no laissez-faire, e a intenção de meu propósito é mostrar como, nas trocas internacionais, a lógica do laissez-faire geralmente leva a circular o pior e a evitar que o melhor circule 3 .

De modo similar, pode-se dizer que a lógica do laissez-faire na circulação dos saberes, inclusive aqueles relativos aos quadros dirigentes, e na formação de pessoal em nível superior (graduação, mestrado e doutorado), permite a transferência/tradução de carga de valores e, no limite, promove o imperialismo cultural, cujo fundamento, conforme observam Bourdieu e Wacquant, repousa "no poder de universalizar os particularismos associados a uma tradição histórica singular [dos dominantes]" (2002, p. 15).

Entretanto, a internacionalização, historicamente, também é capaz de significar compartilhamento e solidariedade, envolvendo a interculturalidade e a partilha do conhecimento, podendo ocorrer restritamente, para elites, ou de forma ampliada, não só para os atores e grupos sociais dominantes (contra-hegemônicos). Assim, circulação internacional das ideias, interpretada aqui como internacionalização acadêmica e internacionalização da educação superior, à luz da categoria de contradição, adquire o sentido humanista da solidariedade e da civilidade ou o sentido privatista, individualista e de formação para a permanência da supremacia dos dominantes ${ }^{4}$.

\footnotetext{
2 "Un programme de recherche scientifique européen sur les relations scientifiques européennes" (2002, p. 4).

3 "En matière de culture comme ailleurs, je ne crois pas au laisser-faire et l'intention de mon propos est de montrer comment, dans les échanges internationaux, la logique du laisser-faire conduit souvent à faire circuler le pire et à empêcher le meilleur de circuler".

4 A internacionalização da educação superior não pode ser confundida com transnacionalização da educação superior. De acordo com Azevedo, "a transnacionalização seria a oferta transfronteiriça de ensino, presencial ou a distância, por intermédio de organizações transnacionais de serviços educacionais com finalidade de lucro. Vale notar, no entanto, que há Instituições de Ensino Superior Privadas com sede no Brasil que são cotadas em bolsa e que têm participação acionária de indivíduos, sociedades, associações e fundos de capitais de origem estrangeira, caracterizando-se, por isso, também como uma modalidade de transnacionalização" (2015a, p. 87). Para análises mais detidas sobre a transnacionalização da educação superior, ver: "Transnacionalização e Mercadorização da Educação Superior: examinando alguns efeitos colaterais do capitalismo acadêmico (sem riscos) no Brasil - a expansão privado-mercantil" (AZEVEDO, 2015a) e "Internacionalização ou Transnacionalização da Educação Superior: entre a formação de um campo social global e um mercado de ensino mundializado (AZEVEDO, 2015b).
} 
Este artigo, de caráter ensaístico, pretende lançar interrogações acerca das possibilidades em relacionar a circulação das ideias e a internacionalização da educação superior, considerando que a problemática pode ensejar múltiplas perspectivas, das quais destacamos:

- a institucional: relativa ao campo universitário brasileiro, em que a distribuição das instituições, a representação dos diferentes grupos sociais em seu interior e a legitimidade buscada pelo alunado via diploma, encerra um tipo de estratégia de internacionalização 'institucionalizada'. Aqui nos referimos diretamente a como certos estabelecimentos buscam a internacionalização como forma de legitimação em face da concorrência;

- a dos pesquisadores: ultrapassando aspectos já tradicionais da internacionalização ligadas à formação no estrangeiro dos acadêmicos e à presença de professores 'de fora' na criação e consolidação das instituições nacionais. Neste caso, aparece uma nova forma de relacionamento, posta em um sistema de trocas acadêmicas centradas na produção coletiva e internacional de pesquisas. As estratégias científicas voltam-se, assim, para mecanismos que utilizam as instâncias nacionais para atingir a legitimidade internacional;

- a dos alunos: em face da recomposição do valor do diploma no mercado educacional em expansão, o que implica em luta maior por sua diferenciação e no mercado de trabalho, com a imposição de novas competências técnicas e sociais. A busca por agregar atributos ao valor social do diploma impulsiona a internacionalização como estratégia para aqueles grupos sociais que entendem estar perdendo posições ou que pretendem garantir o status de distinção por meio do diploma;

- a da validade do conhecimento produzido em uma nova divisão internacional do trabalho científico, em que formas diferenciadas de divisão regional e nacional da produção acadêmica se mesclam ou dão lugar às formas instituídas internacionalmente. As estratégias em direção a um ambiente mundializado da produção de conhecimento pode romper padrões estabelecidos nacionalmente, instigando ou reprimindo a produção mais territorializada.

Acreditamos que esse conjunto de perspectivas interage de variadas maneiras, que mereceriam ser objeto de pesquisas específicas. Aqui tomaremos um dos cenários possíveis permitidos pela noção de campo ao envolver instituições universitárias, pesquisadores, professores, alunos e mediações das agências estatais.

\section{A INTERNACIONALIZAÇÃO DO CAMPO DA EDUCAÇÃO SUPERIOR}

o teu deus é judeu, a tua música é negra, o teu carro é japonês, a tua pizza é italiana, o teu gás é argelino, o teu café é brasileiro, a tua democracia é grega, os teus números são árabes, as tuas letras latinas. Eu sou teu vizinho. E ainda me chamas de estrangeiro?

(EDUARDo GaLEANO, 2016)

A educação superior pressupõe, para além do pensamento nacional e as instituições que lhe dão corpo, a circulação internacional das ideias que, por sua vez, frise-se, não se trata de um fenômeno social neutro, carrega consigo contradições (público $\times$ privado, nacional $\times$ internacional, solidariedade internacional $\times$ imperialismo cultural etc.).

Por um lado, a circulação internacional das ideias pode fundar-se na lógica da solidariedade entre os povos, etnias e nações, pressupondo que a educação e o conhecimento são bens comuns ou bens públicos a serem compartilhados - aqui trata-se de um típico caso de internacionalização da educação superior. Por outro, a circulação internacional das ideias pode basear-se na lógica da competição entre entes privados, situação em que a educação e o conhecimento são contratados em um mercado global e, logo, tratados como mercadorias (commodities), considerada assim transnacionalização da educação superior. Em suma, a educação superior, de forma não distinta de outras atividades que envolvem a distribuição de um bem público na sociedade capitalista, contraditoriamente, tanto pode compor um processo "desinteressado" de integração de campos acadêmicos e universitários como ser considerada um setor de serviços em processo de transnacionalização "interessado" na formação de um mercado mundial (AZEVEDO, 2015, p.75). Em sentido semelhante, conforme Azevedo e Catani,

\footnotetext{
a internacionalização da educação superior e a circulação de ideias para além das fronteiras nacionais são calcadas, esquematicamente, em dois princípios contraditórios: a solidariedade internacional e a concorrência em um mercado global de educação e conhecimento. Essas duas expressões são como oximoros, isso é, um termo silencia o outro. Em geral, quando essas expressões aparecem ao mesmo tempo em uma política de internacionalização é devido à força de retórica (2013, p. 285).
}

Ademais, a circulação internacional de ideias, mesmo que seja proclamada formalmente - em convênios, declarações e protocolos - como um ato 
solidário desinteressado, é uma ação que, interpretada segundo a teoria dos campos de Bourdieu, gera distinção e reconhecimento aos atores sociais envolvidos. Isto porque "todo campo, como o campo científico [...] é um campo de forças e um campo de lutas para conservar ou transformar este mesmo campo de forças" (BOURDIEU, 2004, p. 22-23); não diferente de outros campos, o campo acadêmico é caracterizado por disputas (e alianças) com vistas à conquista de determinados objetos (BOURDIEU, 2004). Para Azevedo, Oliveira e Catani,

o reconhecimento pelos pares, a autoridade científica e a distinção acadêmica são os objetos simbólicos de disputa nesse campo específico. Ao agirem, os atores sociais respondem ao desafio de conquistar maior autonomia do campo acadêmico em relação a outros espaços sociais, em especial ao campo do poder - ou o Estado propriamente dito (2016, p. 784).

Nesse sentido, a internacionalização da educação superior enseja a formação de um campo mundializado de educação superior que, como tal, tende a ser um espaço integrado de trocas de bens simbólicos ${ }^{5}$. Conforme registrou Bourdieu,

nas sociedades altamente diferenciadas o cosmo social é constituído pelo conjunto desses microcosmos sociais relativamente autônomos, espaços de relações objetivas que são o lugar de uma lógica e de uma necessidade específicas e irredutíveis àquelas que regem os outros campos. Por exemplo, o campo artístico, o campo religioso ou o campo econômico obedecem a lógicas diferentes: o campo econômico emergiu, historicamente, enquanto universo no qual, como se diz, 'amigos, amigos, negócios à parte', business is business, e do qual as relações - envoltas em encantamento - de parentesco, amizade e amor são, em princípio, excluídas. Pelo contrário, o campo artístico constituiu-se na e pela recusa, ou inversão, da lei do lucro material (1992, p. 73).

O campo acadêmico, similar ao campo artístico, mais que vantagens materiais, estabelece-se realçando o valor de bens simbólicos como o prestígio e o reconhecimento, angariados principalmente por intermédio de publicações, concursos, conquista de financiamentos e bolsas de pesquisa, participação em redes de pesquisa, atendimento a convites para palestras e cursos, citações, premiações e

\footnotetext{
5 Gisèle Sapiro inicia a definição do verbete "Economia dos Bens Simbólicos" anunciando: "A economia dos bens simbólicos desenvolvida por Bourdieu está enraizada em uma crítica do economicismo que reduz as trocas ao cálculo interessado" (2017, p. 55). A autora, citando indiretamente o trabalho de Bourdieu de 1976, afirma que "o campo científico é outro universo caracterizado pelo interesse no desinteresse quando são preenchidas as condições de sua autonomia. Esse universo tem a seguinte propriedade: os principais clientes das produções são os pares e, portanto, os concorrentes na luta pela autoridade científica" $(2017$, p. 58).
}

nominações honorárias. Estas atividades são exemplos de circulação das ideias em escalas local, regional, nacional ou internacional e constituem objeto de valoração formal nas relações com os pares acadêmicos e com as agências de fomento e de regulação da educação superior (CAPES, CNPq, FINEP, Fundações estaduais de apoio à pesquisa - FAPESP, FAPERJ, Fundação Araucária/Paraná etc.) - mediada por pareceres técnicos-científicos emitidos também pelos pares acadêmicos.

Como abordado por Hey (2012, p.3), o cientista ou acadêmico
tem por delegação produzir um tipo de conhecimento específico, exercendo uma prática social legitimada e reconhecida como tal. A construção do nome atribui o capital simbólico, que é caracterizado pela posição do agente na estrutura de distribuição do capital científico e, sobretudo, como ele é percebido pelos outros pares, igualmente dotados de esquemas de percepção e de apreciação para agirem nesse espaço. (...) A construção do nome atua como mecanismo que posiciona o pesquisador no espaço construído de diferenças.

A legitimidade construída no campo acadêmico, que interrelaciona as instituições de formação, os centros de pesquisa, as associações científicas, as agências de fomento estatais, reflete os espaços e os meandros em que a atividade acadêmica pode se realizar. No Brasil, vale lembrar, a produção acadêmica e a constituição do nome do pesquisador são permeadas pelo aparato estatal de suporte à pesquisa e as possibilidades e constrangimentos daí decorrentes. O princípio dos pares funciona em estado prático, ao criar as normas que serão validadas para a produção e reprodução do conhecimento acadêmico ${ }^{6}$.

Assim, o Sistema de Avaliação da Pós-Graduação no Brasil, desenvolvido pela CAPES, transforma em indicadores as diversas atividades da vida acadêmica. Neste sentido, os programas de Mestrado e Doutorado, para alcançar as mais altas notas de distinção (6 e 7), precisam ser reconhecidos como de alto padrão internacional pelos pares acadêmicos, por intermédio de comissões de avaliação, nucleados na Coordenação de Área junto à CAPES, e referendados pelo CTC-ES da $\mathrm{CAPES}^{7}$. Para ilustrar a caracterização e a importância da

\footnotetext{
${ }^{6}$ Cf. o trabalho de Hey, 2008, acerca do jogo estabelecido no mundo acadêmico em torno da definição legítima do que seja a educação superior no país. E, ainda, Hey (2017), abordando a discussão das determinações extra-acadêmicas nas diferentes posições de elites acadêmicas ou os elementos que compõem o capital científico de elites acadêmicas em ciências humanas (HEY e RODRIGUES, 2017).

7 A avaliação sistemática dos programas de pós-graduação foi instituída em 1977, pela CAPES - Coordenação de Aperfeiçoamento de Pessoal do Ensino Superior. Um Conselho Técnico-Científico da Educação Superior (CTC-ES) e Comissões de Assessores por área foram estabelecidos para executar a avaliação e o acompanhamento dos cursos. Os cursos de mestrado e de doutorado eram avaliados, nesta primeira experiência, com conceitos distribuídos entre: A (muito bom), B (bom), C (regular),
} 
internacionalização para a área de Educação, no Relatório de Avaliação 2013-2016 Quadrienal 2017, aprovado pelo CTC-ES da CAPES, pode-se ler o seguinte:

As notas 6 e 7 foram reservadas exclusivamente para os Programas com doutorado que obtiveram nota 5 e conceitos MB [Muito Bom] em todos os quesitos da ficha de avaliação e que atendam prioritariamente às seguintes condições: a) desempenho equivalente aos centros internacionais de excelência da área; b) nível de desempenho diferenciado em relação aos demais Programas da área; c) solidariedade; e nucleação (...). Os Programas 6 e 7 demonstraram elevado grau de internacionalização, liderança, nucleação e solidariedade, examinados por meio dos seguintes indicadores $^{8}$ : 1. Eventos e cursos internacionais 2. Intercâmbios; 3. Editoração; 4. Redes internacionais; 5. Financiamento e premiações; 6 . Inserção acadêmica e impacto local da internacionalização (CAPES-DAV, 2017, p. 55-56).

Este relatório, especificamente, e a política de avaliação da CAPES, de maneira geral, refletem o que preconiza o Plano Nacional de Pós-Graduação - PNPG (2010-2020) que, logo em sua introdução, ressalta: “a exemplo dos Planos anteriores, também neste a busca da Internacionalização continuará sendo uma das metas maiores do sistema" (CAPES, 2010, p.21). Como é sobejamente sabido, os programas de pós-graduação conceituados nas duas maiores escalas, 6 e 7, recebem maior financiamento e têm maior autonomia de gestão financeira por intermédio do Programa de Excelência

D (fraco) e E (insuficiente). Segundo o portal da CAPES, a partir de 1990 e prevalecendo até hoje, o sistema de avaliação dos programas de pós-graduação utiliza conceitos numerais de 1 a 7: "Os programas recebem notas na seguinte escala: 1 e 2 , tem canceladas as autorizações de funcionamento e o reconhecimento dos cursos de mestrado e/ou doutorado por ele oferecidos; 3 significa desempenho regular, atendendo ao padrão mínimo de qualidade; 4 é considerado um bom desempenho e 5 é a nota máxima para programas com apenas mestrado. Notas 6 e 7 indicam desempenho equivalente ao alto padrão internacional [grifos nossos]" (CAPES, 25, out. 2017).

8 Os indicadores mencionados estão assim compostos: 1. Eventos e cursos internacionais: 1.1 Realização eventos com professores estrangeiros; 1.2 Recebimento de eventos internacionais; 1.3 Recebimento de cursos de professores estrangeiros. 2. Intercâmbios: 2.1 Participação com financiamento de professor estrangeiro visitante no Programa; 2.2 Participação sem financiamento de professor estrangeiro visitante no Programa; 2.3 Participação de professor do Programa como visitantes em universidade estrangeira; 2.4 Realização de Mestrado e Doutorado Sandwich; 2.5 Coorientação internacional; 2.6 Professores do Programa em pós-doutorado internacional; 2.7 Oferecimento de cursos ou vagas no Programa a estrangeiros; 2.8 Participação de alunos do programa em cursos estrangeiros. 3. Editoração: 3.1 Publicação com parceiros internacionais; 3.2 Publicação em periódicos internacionais; 3.3 Atuação como editor de periódico internacional; 3.4 Atuação como avaliador de periódico internacional. 4. Redes internacionais: 4.1 Composição de redes internacionais de pesquisa; 4.2 Composição de projetos internacionais de pesquisa. 5. Financiamento e premiações: 5.1 Obtenção de financiamento de agência internacional; 5.2 Premiações internacionais. 6. Inserção acadêmica e impacto local da internacionalização: 6.1 Gestão científica de órgão internacional; 6.2 Benefício da internacionalização para a graduação.
Acadêmica - PROEX da CAPES ${ }^{9}$. Além disso, seguindo a mesma lógica taxonômica (de classificação) e no esforço de estabelecer uma hierarquia no Sistema de Pós-

Graduação, o PNPG 2011-2020 preconiza tratamento diferenciado para os Programas de Pós-Graduação 6 e 7 em futuras avaliações:

os cursos 6 e 7, que ocupam o topo do sistema, poderão beneficiar-se de uma desregulamentação parcial em suas atividades, permitindo a busca do novo e de experimentações, com o acompanhamento de avaliadores estrangeiros, ficando o monitoramento mais estrito reservado aos demais programas (CAPES, 2010, p. 22).

Nesse sentido, antes de abordar outras questões relativas à circulação internacional das ideias, vale explicitar a categoria teórica "campo social" desenvolvida por Bourdieu. Para isto, de maneira didática e precisa, recorremos a Lahire que, em verbete publicado no Vocabulário Bourdieu, procura condensar as propriedades essenciais de um campo social, embora reconheça as inflexões que "o conceito sofre por ocasião de cada utilização particular que Bourdieu faz dele" (2017, p. 65). Acrescenta, assim, os "elementos fundamentais e relativamente invariantes da definição de campo, suscetíveis de serem extraídos das diferentes obras e artigos do autor sobre a questão" (2017, p. 65). Apoiando-se, em especial, em dois trabalhos de Bourdieu (Le champ littéraire, ARSS, n. 89, p.3-46, 1991; Quelques propriétés des champs. In: Questions de Sociologie. Paris: Minuit, 1980), Lahire compila as seguintes definições de campo social, (pede-se desculpas pela longa citação, mas vale a transcrição sintética do comentarista):

- Um campo é um microcosmo incluído no macrocosmo constituído pelo espaço social global (nacional ou, mais raramente, internacional).

- Cada campo possui regras do jogo e desafios específicos, irredutíveis às regras do jogo e aos desafios dos outros campos. Por exemplo, o que mobiliza o matemático - e a maneira como mobiliza - nada tem a ver com o que mobiliza - e a maneira como o

\footnotetext{
9 De acordo com informações da CAPES, o PROEX tem por objetivo "manter o padrão de qualidade dos programas de pós-graduação com nota 6 ou 7, pertencentes a instituições jurídicas de direito público e privado, atendendo adequadamente suas necessidades e especificidades" (CAPES, 24 out 2017). Em relação ao financiamento, ainda segundo a CAPES, "os Programas inseridos no Proex recebem uma dotação orçamentária que pode ser utilizada de acordo com prioridades estabelecidas pelos próprios programas, em qualquer das modalidades de apoio concedidas pela CAPES: concessão de bolsas de estudo, bem como recursos de custeio fomento para investimento em laboratórios, custeio de elaboração de dissertações e teses, passagens, eventos, publicações, entre outros. As bolsas de estudo concedidas no âmbito do Proex são gerenciadas pelas coordenações dos cursos de pós-graduação, que são responsáveis pela seleção e acompanhamento dos bolsistas conforme as orientações da CAPES" (CAPES, 24 out. 2017).
} 
faz - um industrial ou um grande costureiro. Os interesses sociais são sempre específicos a cada campo e, portanto, não se reduzem ao interesse de tipo econômico.

- Um campo é um 'sistema' ou um 'espaço' estruturado de posições ocupadas pelos diferentes agentes do campo. As práticas e estratégias dos agentes só se tornam compreensíveis se forem relacionadas às suas posições no campo. Entre as estratégias invariantes, encontra-se a oposição entre as estratégias de conservação e as estratégias de subversão do estado da relação de forças existente: as primeiras são mais frequentemente as estratégias dos dominantes, enquanto as segundas correspondem às dos dominados (e, entre eles, mais particularmente, dos 'recém-chegados' no campo). Essa oposição pode assumir a forma de um conflito entre 'velhos' e 'novos', 'ortodoxos' e 'heterodoxos', 'conservadores' e 'revolucionários' etc.

- Esse espaço é um espaço de lutas, uma arena onde está em jogo uma concorrência ou competição entre os agentes que ocupam as diversas posições.

- O objetivo dessas lutas reside na apropriação do capital específico do campo (obtenção do monopólio do capital específico legítimo) e/ou a redefinição desse capital.

- Esse capital é desigualmente distribuído no seio do campo. Por conseguinte, existem, nele, dominantes e dominados. A distribuição desigual do capital determina a estrutura do campo que é definido, portanto, pelo estado de uma relação de forças histórica entre as forças (agentes e instituições) em confronto no campo.

- Em luta uns contra os outros, todos os agentes de um campo têm, contudo, interesse em que o campo exista. Eles mantêm, portanto, uma 'cumplicidade objetiva' para além das lutas que os opõem.

- A cada campo corresponde um habitus (sistema de disposições incorporadas) próprio do campo (habitus filológico, habitus jurídico, habitus futebolístico etc). Apenas os que tiverem incorporado o habitus próprio do campo estão em condições de disputar o jogo e de acreditar na importância dele.

- Todo campo possui uma autonomia relativa: as lutas que se desenrolam em seu interior têm uma lógica própria, mesmo que os resultados das lutas (econômicas, sociais, políticas etc.) externas ao campo pese fortemente no desfecho das relações de força internas (2017, p. 65).

Dados estes esclarecimentos, pode-se dizer que a teoria dos campos de Bourdieu auxilia a compreender a lógica da circulação internacional das ideias ou, de forma mais abrangente, a internacionalização da educação superior. Dessa maneira, entre as modalidades de circulação internacional das ideias, não é ocioso dizer, os intercâmbios científicos e a formação de pessoal no exterior não se circunscrevem a história recente. Para Monique de Saint Martin, é necessário "precaver-se contra a ideia de que as trocas e a circulação de intelectuais e cientistas sejam uma novidade radical" (2004, p. 17). Para o caso brasileiro, vale lembrar o processo de criação das modernas instituições universitárias, caso da Universidade de São Paulo, em 1934, e a influência das missões francesas na formação dos quadros intelectuais do período (cf. HEY e CATANI, 2006; Cardoso, 1982), ou a influência de fundações estrangeiras na criação e modernização dos centros de pesquisas (cf. MICELI, 1993) ou, ainda, o investimento maciço da Capes e do CNPq na formação pós-graduada no exterior ocorrida nos anos 1970 (cf. HEY, 2008).

Correlativamente, os acadêmicos na condição de professores, atores sociais salientes do campo da educação superior, ao dirigirem seus esforços para a formação acadêmica de estrangeiros, promovem a internacionalização do campo acadêmico nacional em que se encontram. Em consequência, estabelecem intersecções entre os espaços ocupados pelo agente formador e pelo agente em processo de formação, possibilitando meios de unificação ou de integração dos campos acadêmicos conectados por representantes das elites dominantes no processo de formação. De acordo com Anne-Catherine Wagner,

ao servirem de preparação para a mobilidade, as formações internacionais são ajustadas às novas exigências da produção: o domínio das línguas, as familiaridades com os meios de negócios exteriores, a possibilidade de organizar sua carreira em vários países são competências que assumem uma crescente importância em relação com a mundialização das trocas. As escolas aparecem como instâncias de reprodução em que as frações mais internacionais das classes superiores dos diferentes países colocam em comum e transmitem coletivamente seus recursos específicos (WAGNER, 2002, p. 174-175).

Tendo ainda por referência a teoria dos campos sociais de Bourdieu, não seria ousado afirmar que a assim denominada internacionalização da educação superior é, na prática, a constituição de um campo internacional de educação superior. Caracterizado como um espaço de lutas e disputas pelo capital específico do campo, é ocupado por atores sociais em posições de dominantes e dominados, que expressam inclinações advindas do papel das trocas internacionais nas sociedades diferenciadas contemporâneas, a exemplo das tendências nacionalistas e imperialistas, desenvolvimentistas e "dependentistas" etc. Em suma, a constituição de um campo internacional da educação superior implica necessariamente em falar de desnacionalizações e disputas por soberanias (gerais e específicas). Para ilustrar, tome-se o exemplo das políticas no Brasil e na Argentina em favor do "Consenso de 
Washington"10 e a agenda de desnacionalizações dos anos 1990, defendida aguerridamente pelos quadros ocupantes de postos de comando nos Ministérios da Fazenda (Brasil) e da Economia (Argentina). Segundo Azevedo e Catani,

os quadros internacionalizados, esta categoria particular de atores sociais, são mais fiéis aos organismos e instituições que lhes forneceram o substrato culturalideológico e, consequentemente, à sua visão de mundo que ao seu empregador público (o Estado) ou mesmo à coligação político partidária no poder (...) (2004, p. 169).

Neste mesmo texto, Azevedo e Catani (2004) chamam a atenção para a perspicaz análise feita por Celso Lafer e Felix Peña, ainda em 1973, a respeito da influência estrangeira na formatação de políticas no Brasil e na Argentina. Lafer e Peña afirmam que

os atores nacionais orientam suas ações para atores nacionais de outra unidade política do sistema internacional para obterem destes um comportamento favorável a seus objetivos. Em certos casos, assumem o caráter de ator "interno" para um determinado sistema político e passam a participar, internamente, de uma maneira direta ou indireta, no exercício da autoridade política (...). A vinculação por penetração se articula com base na existência de atores internos de um sistema político nacional, com lealdades duais, uma delas orientada para um centro de decisão externo (...) (apud AZEVEDO; CATANI, 2004, p. 164).

Aliás, este pensamento está de acordo com o que observa Anne-Catherine Wagner que, retomando um trabalho de pesquisa de Monique de Saint Martin a respeito da mobilidade internacional das elites, afirma que "as novas nobrezas nacionais tendem cada vez mais a se internacionalizar, tanto em seu funcionamento quanto em sua formação e reprodução" (WAGNER, 2017, p.273). Isto é, o campo da formação das elites dirigentes mundiais está se unificando ou, se preferir, está se integrando globalmente, permitindo aos herdeiros nacionais a busca de formação internacional como mais um recurso de preparo intelectual, de disposição e de afirmação de sua

\footnotetext{
${ }^{10}$ Consenso de Washington é a expressão que define uma agenda de reformas liberalizantes, baseada em texto-referência sugerido por John Williamson para o Seminário organizado no Institute for International Economics, em 1989, em que participaram autoridades dos EUA, de países da América Latina, do Fundo Monetário Internacional (FMI) etc. Ayerbe sistematiza em três categorias a agenda do Consenso de Washington: "1. Equilíbrio das contas públicas, obtido preferencialmente a partir da redução de despesas e não pelo aumento de impostos. A diminuição de gastos não deve afetar áreas como saúde e educação, mas sim os subsídios outorgados a empresas públicas e privadas. 2. Liberalização da economia, com abertura comercial e desregulamentação, reduzindo os controles governamentais sobre o setor privado e eliminando a discriminação em relação ao capital estrangeiro. 3. Privatização, transferindo para o setor privado as empresas do Estado" (1998, p. 28).
}

condição social dirigente. Mas vale a pena refletir sobre como a formação de um campo internacional da educação superior está em processo de construção e quais os efeitos para as estruturas universitárias e acadêmicas em âmbito nacional. Internacionalizar a educação superior leva a processos específicos de reconfiguração das instituições universitárias e da produção acadêmica, enquanto que tornar o campo da educação superior internacional leva à implementação de novas dinâmicas e jogos que tendem a sedimentar o mercado nacional da educação superior e da produção de conhecimento. Se, na primeira situação a educação superior pode simplesmente ser agregada pelos aspectos relativos ao internacional (intercâmbios, dupla titulação etc.) na segunda o campo pode ser levado a estruturar-se por parâmetros importados que tendem a segmentar e a produzir desigualdades agudas no processo de formação e reprodução universitária e acadêmica.

\section{CONSIDERAÇÕES FINAIS}

substituir uma relação prática de pré-ocupação, presença imediata de um por vir inscrito no presente, por uma consciência racional, calculista, que se coloca objetivos como tais, como possíveis, é abrir espaço para a questão do cinismo, que coloca como tais objetivos inconfessáveis. Ao passo que, se minha análise está correta, podemos, por exemplo, ajustar-nos às necessidades de um jogo, podemos fazer uma belíssima carreira acadêmica, sem nunca ter a necessidade de postular tal objetivo

(PIERre BourdieU, 1996))

O presente artigo foi iniciado com perguntas sobre a lógica da circulação das ideias e da internacionalização da educação superior. Assim, buscou-se aqui demonstrar o conceito de campo social em Pierre Bourdieu, bem como algumas explicações sobre como os acadêmicos têm participado do processo de internacionalização ou de circulação internacional das ideias. As práticas possíveis de serem distinguidas como internacionais, foram cotejadas pelo auxílio dos aportes da teoria dos campos sociais de Bourdieu e do Relatório da Área de Educação publicado pela CAPES em 2017, auxiliando nas definições e exemplos.

Nesse sentido, sendo o campo da educação superior um espaço de lutas, de circulação e de distribuição de bens públicos e de bens comuns, em longos rituais de iniciação e de consagração na esfera pública, é passível de ser interpretado também como um espaço de trocas de bens simbólicos, sobretudo caros objetos para o campo acadêmico como o "prestígio" e o "reconhecimento". Isto se dá no Brasil, vale notar, contudo, em um contexto de crise, com cortes e contingenciamento de verbas públicas 
para a ciência, tecnologia e inovação, em especial após a implantação do Novo Regime Fiscal - Emenda 95/2016 (AZEVEDO, 2016; BRASIL, 2016), no decorrer da chamada "quarta revolução tecnológica" ou da smart factory (da indústria inteligente), que é caracterizada pela automação, pelo sistemas cibernéticos, pela Internet das coisas e pela computação em nuvens (SCHWAB, 2015; AZEVEDO, OLIVEIRA e CATANI, 2016; GOUVEIA, AZEVEDO, MENDES, 2017); em época de "economia baseada no (cercamento do) conhecimento" (AZEVEDO, 2013) e da mercadorização e da transnacionalização da Educação Superior (AZEVEDO, 2015a, 2015b).

Ademais, a internacionalização da educação superior não pode ser desenvolvida como um fim em si mesmo, mas se constitui em um processo de integração das dimensões internacional, intercultural e global à prática dos atores centradas em espaços nacionais, tendendo à formação de um campo global acadêmico (AZEVEDO, 2014). Em entrevista a João Marcos Veiga para o portal da Anped, um dos autores deste artigo destaca que os acadêmicos demonstram a prática internacionalizada por intermédio de ações como:

a mobilidade transfronteiriça de estudantes e professores, as parcerias e convênios com instituições estrangeiras e a docência e a comunicação de resultados de pesquisa em línguas estrangeiras. Entretanto, tais ações necessariamente não correspondem automaticamente ao que se conceitua como internacionalização. Há um sério perigo de se estar carreando esforços para a transnacionalização da educação superior, algo mais próximo da formação de um mercado global de educação superior. A prova de que se está fazendo internacionalização e não transnacionalização seria atentar se as ações e as políticas de promoção da circulação internacional das ideias consideram os princípios de solidariedade, reciprocidade, interculturalidade, justiça social e respeito mútuo. Assim, sem querer fornecer uma receita, mas os atores sociais comprometidos com estes valores podem balizar suas ações por estes princípios, procurando isentarem-se de carrear esforços para a formação de um mercado mundializado ou transnacionalizado de ensino superior, em que a competição, os rankings e a educação como mercadoria tornem-se preponderantes (AZEVEDO, 2017).

\section{REFERÊNCIAS}

AYERBE, Luis Fernando. Neoliberalismo e Política externa na América Latina. São Paulo: Editora UNESP, 1998.

AZEVEDO, Mário L. N. Transnacionalização e Mercadorização da Educação Superior: examinando alguns efeitos colaterais do capitalismo acadêmico (sem riscos) no Brasil - a expansão privado-mercantil. Rev. Inter. Educ. Superior [RIESup] Campinas, SP, v. 1, n. 1, p. 86-102, jul.-set. 2015a.
AZEVEDO, Mário L. N. Internacionalização ou Transnacionalização da Educação Superior: entre a formação de um campo social global e um mercado de ensino mundializado. Crítica Educativa Sorocaba, SP, v. 1, n. 1, p. 56-79, jan.-jun. 2015 b.

AZEVEDO, Mário L. N. A internacionalização da Educação Superior em questão: mitos, enganos e verdades. Horizontes LatinoAmericanos - Revista de Humanidades e Ciências Sociais do Mercosul Educacional, v. 3, n. 1, p. 99-110, 2014.

AZEVEDO, Mário L. N. O Novo Regime Fiscal: A Retórica da Intransigência, o Constrangimento da oferta de bens públicos e o comprometimento do PNE 2014-2024. Tópicos Educacionais, Recife, v. 22, n. 1, jan.-jun. 2016.

AZEVEDO, Mário L. N. Internacionalização da Educação. Entrevista concedida a João Marcos Veiga. Portal da ANPEd. 2017. Disponível em: <http://www.anped.org.br/ news/entrevista-mario-azevedo-uem-internacionalizacao-daeducacao $>$. Acesso em: 25 out. 2017.

AZEVEDO, Mário L. N. Educação superior, internacionalização e circulação de ideias: ajustando os termos e desfazendo mitos. Inter-Ação, Goiânia, v. 38, n. 2, p. 273-291, maio-ago. 2013.

AZEVEDO, Mário L. N.; CATANI, Afrânio M. Universidade e Neoliberalismo: o Banco Mundial e a Reforma Universitária na Argentina (1989-1999). Londrina: Práxis, 2004.

AZEVEDO, Mário L. N.; OLIVEIRA, João F.; CATANI, Afrânio M. O Sistema Nacional de Pós-graduação (SNPG) e o Plano Nacional de Educação (PNE 2014-2024): regulação, avaliação e financiamento. RBPAE, v. 32, n. 3, p. 783-803, set.-dez. 2016.

BOURDIEU, Pierre. Questions de Sociologie. Paris: Les Éditions de Minuit, 1984.

BOURDIEU, Pierre. Razões Práticas: sobre a teoria da ação. Campinas, SP: Papirus, 1996.

BOURDIEU, Pierre. Les conditions sociales de la circulation internationale des idées. Actes de la recherche en sciences sociales [ARSS], v. 145, décembre 2002. La circulation internationale des idées. p. 3-8.

BOURDIEU, Pierre. Os usos sociais da ciência. Por uma sociologia clínica do campo científico. São Paulo: EdUNESP, 2004.

BOURDIEU, Pierre; WACQUANT, Loïc. Réponses: pour une anthropologie reflexive. Paris: Seuil, 1992.

BOURDIEU, Pierre; WACQUANT, Loïc. Sobre as Artimanhas da Razão Imperialista. Estudos Afro-Asiáticos, ano 24, n. 1, p. 15-33, 2002.

BRASIL. EC 095 - Novo Regime Fiscal. Brasília: Câmara Federal, 2016.

CAPES. Sobre Avaliação de Cursos. Extraído de: <http:// www.capes.gov.br/acessoainformacao/perguntas-frequentes/ avaliacao-da-pos-graduacao/7421-sobre-avaliacao-de-cursos>. Acesso em: 25 out. 2017.

CAPES. Programa de Excelência Acadêmica (Proex). Extraído de: <http://www.capes.gov.br/acessoainformacao/ perguntas-frequentes/avaliacao-da-pos-graduacao/7421-sobreavaliacao-de-cursos>. Acesso em: 24 out. 2017.

CAPES. Relatório de Avaliação 2013-2016. Quadrienal 2017: Área de Educação. Brasília, 2017. 
CAPES. Plano Nacional de Pós-Graduação - PNPG 20112020. Brasília, DF, 2010. 2 v.

CARDOSO, Irene A. R. A universidade da comunhão paulista - o projeto de criação da universidade de São Paulo. São Paulo: Autores Associados/Cortez, 1982.

GALEANO, Eduardo. O caçador de histórias. Porto Alegre: L\&PM, 2016.

GOUVEIA, Andréa B.; AZEVEDO, Mário L. N.; MENDES, Geovana M. L. A Pós-Graduação e a Internacionalização da Educação Superior: tendências e problemas - o lugar da ANPEd. Plurais - Revista Interdisciplinar, Salvador, v. 2, n. 2, p. 10-26, abr.-ago. 2017.

HEY, Ana Paula. Esboço de uma sociologia do campo acadêmico: a educação superior no Brasil. São Carlos, SP: EdUFSCar; São Paulo, FAPESP, 2008.

HEY, Ana Paula. Elites científicas: o caso da Academia Brasileira de Ciências. Anais do 360 Encontro Anual da ANPOCS, Águas de Lindóia, SP, 21-25 outubro 2012.

HEY, Ana Paula. Les élites des Sciences Sociales au Brésil : les ruses entre les usages du pouvoir académique et les rapports avec l'État. Annalles du XVII Congress de l'Académie Française de Sociologie. Amiens, France, 03-06 Juillet 2017.

HEY, Ana Paula; CATANI, Afrânio M. A USP e a formação de quadros dirigentes. In: MOROSINI, Marília (Org.). A universidade no Brasil: concepções e modelos. Brasília: INEP, 2006. p. 295-312.

HEY, Ana Paula; RODRIGUES, Lidiane S. Elites acadêmicas: as Ciências Sociais na Academia Brasileira de Ciências. Revista Tempo Social, USP, 2017 (no prelo).
LAFER, Celso; PEÑA, Felix. Argentina e Brasil no Sistema das Relações Internacionais. São Paulo: Duas Cidades, 1973.

LAHIRE, Bernard. Campo (Verbete). In: CATANI, A. M.; NOGUEIRA, M. A.; HEY, A. P.; MEDEIROS, C. Vocabulário Bourdieu. Belo Horizonte: Autêntica, 2017.

MICELI, Sergio. A Fundação Ford no Brasil. São Paulo: FAPESP/Sumaré, 1993.

MOROSINI, Marília; NASCIMENTO, Lorena Machado do. Internacionalização da Educação Superior no Brasil: a produção recente em teses e dissertações Educação em Revista, Belo Horizonte, n. 33, e155071, 2017.

SAPIRO, Gisèle. Bens Simbólicos [Economia dos] (Verbete). In: CATANI, A. M.; NOGUEIRA, M. A.; HEY, A. P.; MEDEIROS, C. Vocabulário Bourdieu. Belo Horizonte: Autêntica, 2017.

SCHWAB, Klaus. The Fourth Industrial Revolution: what it means, how to respond. Foreign Affairs, 12, Dec. 2015.

WAGNER, Anne-Catherine. A mobilidade das elites e as escolas internacionais - As formas específicas de representar o nacional. In: ALMEIDA, Ana Maria F.; NOGUEIRA, Maria Alice (Org.). A Escolarizacao das elites: um panorama internacional da pesquisa. Petrópolis, RJ: Vozes, 2002, p. 169-181.

WAGNER, Anne-Catherine. Mundialização/Internacionalização. In: CATANI, A. M.; NOGUEIRA, M. A.; HEY, A. P.; MEDEIROS, C. Vocabulário Bourdieu. Belo Horizonte: Autêntica, 2017.

Recebido em 30-08-2017. Aprovado em 25-11-2017. 